\title{
The Effects of Treatment on Body Mass Index in Giant Cell Arteritis: A Post Hoc Analysis of the GiACTA Trial
}

\author{
Naomi J. Patel (D) X Xiaoqing Fu · Yuqing Zhang · Sebastian H. Unizony (D) \\ Zachary S. Wallace (D) · Hyon K. Choi (D) · John H. Stone iD
}

Received: September 20, 2021 / Accepted: November 30, 2021 / Published online: December 25, 2021

(C) The Author(s) 2021

\begin{abstract}
Introduction: Giant cell arteritis (GCA) requires treatment with high-dose, long-term glucocorticoids (GCs), and tocilizumab is often used early in the treatment paradigm. Weight gain, which is associated with morbidity and mortality, is a major concern for patients, though the factors that contribute to changes in body mass index (BMI) throughout the treatment of GCA are poorly understood.

Methods: We analyzed GCA patients enrolled in the GiACTA (Tocilizumab in Giant Cell Arteritis) trial. We used univariable and multivariable mixed-effects modeling to examine the association between changes in BMI and cumulative GC dose, disease status at baseline (newly diagnosed versus relapsing), randomization to tocilizumab, and disease flares.

Results: A total of 250 patients were included (75\% females, mean age 69 years). The mean \pm SD BMI change over 52 weeks was
\end{abstract}

N. J. Patel · X. Fu · Y. Zhang · S. H. Unizony ·

Z. S. Wallace · H. K. Choi · J. H. Stone $(\bowtie)$

Division of Rheumatology, Allergy and

Immunology, The Edward A. Fox Chair in Medicine,

Massachusetts General Hospital, Medicine Harvard

Medical School, Boston, MA, USA

e-mail: jhstone@mgh.harvard.edu

X. Fu · Y. Zhang · Z. S. Wallace · H. K. Choi

Clinical Epidemiology Program, Department of

Medicine, Massachusetts General Hospital, Mongan

Institute, Boston, MA, USA
$1.18 \pm 1.98 \mathrm{~kg} / \mathrm{m}^{2}$. On multivariable analysis, cumulative prednisone dose at 52 weeks was independently associated with BMI increase ( $\beta=0.94 \mathrm{~kg} / \mathrm{m}^{2}$ for $0-1 \mathrm{~g}$ exposure; $\beta=1.40 \mathrm{~kg} /$ $\mathrm{m}^{2}$ for $\geq 4 \mathrm{~g}$ exposure; $p$ for trend $\left.<0.001\right)$. Relapsing disease at baseline $\left(\beta=-0.42 \mathrm{~kg} / \mathrm{m}^{2}\right.$ compared to those with newly diagnosed disease; $p=0.002$ ) and flares over 52 weeks in newly diagnosed patients $\left(\beta=-0.18 \mathrm{~kg} / \mathrm{m}^{2}\right.$ per flare; $p=0.03$ ) were independently associated with lower BMI increase.

Conclusions: Cumulative prednisone exposure is associated with increased BMI in GCA patients. In those with newly diagnosed disease, effective disease control regardless of the treatment used also contributes to BMI increase. Modest weight gain may be an indicator of adequate treatment response.

Keywords: Body mass index; Giant cell arteritis; Glucocorticoid; Vasculitis 


\section{Key Summary Points}

\section{Why carry out this study?}

Weight gain is associated with morbidity and mortality and is a major concern for patients receiving glucocorticoids for treatment of rheumatic disease.

We aimed to identify factors associated with changes in body mass index (BMI) in patients with giant cell arteritis over the 52-week Trial of Tocilizumab in Giant Cell Arteritis, in which patients were randomized to tocilizumab and glucocorticoids or glucocorticoids alone, and to determine whether tocilizumab affects the relationship between glucocorticoid dose and change in BMI.

We hypothesized that cumulative glucocorticoid exposure would be positively associated with change in BMI and that disease activity or flares would be negatively associated with change in BMI.

\section{What was learned from the study?}

On multivariable adjusted analyses, we found that cumulative prednisone dose over 52 weeks was independently associated with BMI increase $(\beta=0.94 \mathrm{~kg} /$ $\mathrm{m}^{2}$ for $0-1 \mathrm{~g}$ exposure; $\beta=1.40 \mathrm{~kg} / \mathrm{m}^{2}$ for $\geq 4$ g exposure; $p$ for trend $<0.001$ ) while relapsing disease at baseline $(\beta=-0.42$ $\mathrm{kg} / \mathrm{m}^{2}$ compared to those with newly diagnosed disease; $p=0.002$ ) and flares over 52 weeks in newly diagnosed patients $\left(\beta=-0.18 \mathrm{~kg} / \mathrm{m}^{2}\right.$ per flare; $\left.p=0.03\right)$ were independently associated with lower BMI increase.

Cumulative glucocorticoid exposure over 52 weeks is significantly associated with change in BMI though effective disease control also contributes to BMI increase in patients with newly diagnosed giant cell arteritis.

A modest increase in BMI may actually be an indicator of effective disease control regardless of treatment regimen.

\section{INTRODUCTION}

Giant cell arteritis (GCA) is a form of large vessel vasculitis characterized by granulomatous inflammation and giant cell formation. It classically affects the temporal arteries but can also involve larger vessels, including the aorta and primary aortic branches. Until recently, there was no alternative treatment to long-term, high-dose glucocorticoid (GC) tapers. GCs are associated with numerous toxicities, one of which —weight gain—is an especially important concern for patients and can affect medication adherence [1-3]. Moreover, weight gain has also been associated with increased morbidity and mortality $[4,5]$. Thus, identifying factors associated with change in body mass index (BMI) during the treatment of chronic inflammatory disease is important to inform care and help to address patient expectations.

Several studies have evaluated the effects of biologic immunosuppressants and GCs on weight gain in other rheumatic diseases, particularly anti-neutrophil cytoplasmic antibody (ANCA)-associated vasculitis (AAV) and rheumatoid arthritis [6-8]. These studies have demonstrated associations between disease activity, newly diagnosed as opposed to relapsing disease, and specific treatments and changes in weight or BMI [6-8]. However, results have been mixed in regard to the relationship of cumulative GC dose with weight gain and BMI change. To date, no study has analyzed the impact of treatment on weight or BMI change in GCA. While GCs remain central to the treatment of GCA, tocilizumab, an interleukin6 receptor (IL-6R) blocker, is now frequently used as a steroid-sparing agent for remission maintenance [9]. As randomized controlled trials have demonstrated that tocilizumab spares the use of GCs, the effect of tocilizumab on changes in BMI is of particular interest in GCA [9].

We analyzed data from the Trial of Tocilizumab in Giant Cell Arteritis (GiACTA), a randomized, double-blind, placebo-controlled trial in which patients with either newly diagnosed or relapsing GCA received treatment with either prednisone alone or prednisone in combination 
with tocilizumab [9]. We aimed to evaluate changes in BMI over the 52-week treatment period to identify factors associated with BMI change and to determine whether tocilizumab affects the relationship between GC dose and BMI change.

\section{METHODS}

\section{GiACTA Trial}

Details of the GiACTA trial design have been reported previously [9]. Briefly, GCA patients 50 years of age or older were enrolled. GCA was diagnosed either by positive temporal artery biopsy or by imaging demonstrating large-vessel vasculitis. Patients with either newly diagnosed or relapsing disease were included. Patients were randomized to receive either tocilizumab or placebo in conjunction with a GC taper. The four randomization groups were: (1) weekly subcutaneous tocilizumab at a dose of $162 \mathrm{mg}$ plus a 26-week prednisone taper; (2) subcutaneous tocilizumab at a dose of $162 \mathrm{mg}$ every other week plus a 26-week prednisone taper; (3) weekly subcutaneous placebo plus a 26-week prednisone taper; or, (4) weekly subcutaneous placebo plus a 52-week prednisone taper. The primary endpoint was sustained-GC-free remission at 52 weeks. The original clinical trial (Trial of Tocilizumab in Giant Cell Arteritis) was approved by the respective Institutional Review Board at each participating institution and was conducted in accordance with the Declaration of Helsinki. Written informed consent was obtained from all study participants.

\section{Glucocorticoid Assessment}

Patients' cumulative GC exposure after the baseline visit was assessed at weeks 12, 24, and 52. GCs received before the baseline visit were not considered in this analysis because those data were not available. For the purposes of this study, methylprednisolone doses were converted to the equivalent prednisone dose. The cumulative dose of prednisone equivalents in milligrams (mg) was recorded at each time point for each patient. Baseline prednisone dose was stratified by greater or less than $30 \mathrm{mg}$ daily.

\section{BMI Assessment}

The patient's weight in kilograms was measured at baseline and at weeks 24 and 52. Height, measured at the baseline visit, was assumed to be stable throughout the trial. BMI was calculated in $\mathrm{kg} / \mathrm{m}^{2}$ at weeks $0,12,24$, and 52 . At baseline, patients were categorized according to the World Health Organization definitions of underweight $\left(\mathrm{BMI}<18.5 \mathrm{~kg} / \mathrm{m}^{2}\right)$, normal weight (BMI 18.5 to $<25 \mathrm{~kg} / \mathrm{m}^{2}$ ), overweight (BMI 25.0 to $<30 \mathrm{~kg} / \mathrm{m}^{2}$ ), and obese (BMI 30.0 $\mathrm{kg} / \mathrm{m}^{2}$ or greater). BMI change throughout the trial was assessed continuously and categorically as: (1) $\geq 5 \mathrm{~kg} / \mathrm{m}^{2}$ decrease, (2) $>2$ to $<5 \mathrm{~kg} / \mathrm{m}^{2}$ decrease, (3) $0-2 \mathrm{~kg} / \mathrm{m}^{2}$ increase or decrease, (4) increase of $>2$ to $<5 \mathrm{~kg} / \mathrm{m}^{2}$, or (5) increase of $\geq 5 \mathrm{~kg} / \mathrm{m}^{2}$. These categories were chosen as they correspond to item groupings in the BMI domain of the glucocorticoid toxicity index (GTI), a clinical trial outcome measure that quantifies the change in GC toxicity over time [10]. BMI change was calculated for patients with available BMI data at weeks 0 and $52(N=197)$ and weeks 0 and $24(N=230)$. Thus, patients who withdrew from the trial or did not have any available BMI at week 24 or 52 were excluded from these analyses. In the mixed-effects models, fixed-effects observations for which a covariate had missing data were deleted. Missing data were assumed to be missing at random, and all available data points throughout the trial were included in the models.

\section{Statistical Analysis}

Continuous variables were reported as mean \pm standard deviation (SD) or $95 \%$ confidence interval (95\% CI). Categorical variables were reported as number (\%). Unpaired and paired student $t$ tests were used to evaluate differences in body mass index over time and between groups of patients. We used a mixedeffects multiple regression model to estimate the effect of different factors including 
cumulative glucocorticoid exposure, relapsing versus newly diagnosed disease at baseline, randomization to tocilizumab, and disease flares of disease on changes in BMI over the 52 weeks of the trial in univariable and multivariable models. We divided cumulative prednisone exposure into six categories: 0 (reference), $>0 \quad$ to $<1 \mathrm{~g}, \geq 1$ to $<2 \mathrm{~g}, \geq 2$ to $<3 \mathrm{~g}$, $\geq 3$ to $<4 \mathrm{~g}$, and $\geq 4 \mathrm{~g}$, and tested for linear trend by entering the median value of cumulative prednisone from each category into the regression model. We adjusted for confounders for each risk factor under the guidance of a causal diagram, with variables including cumulative glucocorticoid dose, flares, randomization to tocilizumab, relapsing disease at baseline, age, sex, baseline BMI, and baseline prednisone dose. A Wilcoxon rank-sum test was used to compare the flares and cumulative prednisone exposure between different groups. We used SAS, version 9.4, for all statistical analyses.

Table 1 Baseline features of the GIACTA cohort

\begin{tabular}{lc}
\hline Variable $(\boldsymbol{N}=\mathbf{2 5 0})$ & \multicolumn{1}{c}{ Value } \\
\hline Age, mean (SD) & $69(8)$ \\
Female, no (\%) & $187(75)$ \\
Disease category, no (\%) & $119(48)$ \\
Newly diagnosed & $131(52)$ \\
Relapsing & \\
Body mass index (BMI) & $25.9(4.7)$ \\
Baseline BMI, mean (SD) & $7(3)$ \\
Underweight, no (\%) & $115(46)$ \\
Normal weight, no (\%) & $85(34)$ \\
Overweight, no (\%) & $43(17)$ \\
Obese, no (\%) & $129(52)$ \\
Baseline prednisone dose & $121(48)$ \\
Less than or equal to 30 mg daily & \\
Greater than 30 mg daily &
\end{tabular}

GiACTA trial of tocilizumab in giant cell arteritis

\section{RESULTS}

\section{Baseline Cohort Demographics}

There were 251 patients enrolled in the GiACTA trial; one patient withdrew prior to randomization and was not included in the analyses. Thus, 250 patients were included in our analyses. The mean \pm SD age was $69 \pm 8$ years and $187(75 \%)$ were female (Table 1 ). The mean \pm SD baseline BMI was $25.9 \pm 4.7 \mathrm{~kg} / \mathrm{m}^{2}$. A slight majority of patients $(131,52 \%)$ had relapsing disease at baseline; the remainder had newly diagnosed disease. Of the 250 patients included, seven (3\%) were classified at baseline as being underweight; 115 (46\%) as having normal weight; 85 $(34 \%)$ as being overweight; and $43(17 \%)$ as obese. The baseline prednisone dose was less than or equal to $30 \mathrm{mg}$ daily in 129 patients (52\%) and greater than $30 \mathrm{mg}$ daily in 121 patients (48\%).

\section{Glucocorticoid Administration During the Trial}

Over the course of the 52-week trial, patients were treated with a mean \pm SD cumulative prednisone dose of $3077 \pm 2577 \mathrm{mg}$. The greatest GC exposure occurred during the first 24 weeks of the trial, when patients received a mean of $1999 \pm 1421 \mathrm{mg}$-approximately two thirds of their overall GC exposure. Between weeks 24 and 52, patients received a mean of $1035 \pm 1448 \mathrm{mg}$-approximately one-third of their overall GC exposure. Patients who were randomized to tocilizumab received less prednisone than those randomized to prednisoneonly ( 2191 vs. $4318 \mathrm{mg}$ ). Patients with relapsing and newly diagnosed disease received similar amounts of prednisone (3006 vs. $3149 \mathrm{mg}$, respectively). Patients who experienced disease flares received more prednisone than those who did not flare (4732 vs. $1712 \mathrm{mg}$ ).

\section{BMI Change During the Study}

The mean BMI increased from $25.9 \pm 4.7$ at baseline to $27.1 \pm 4.9$ at 24 weeks, and then 
a

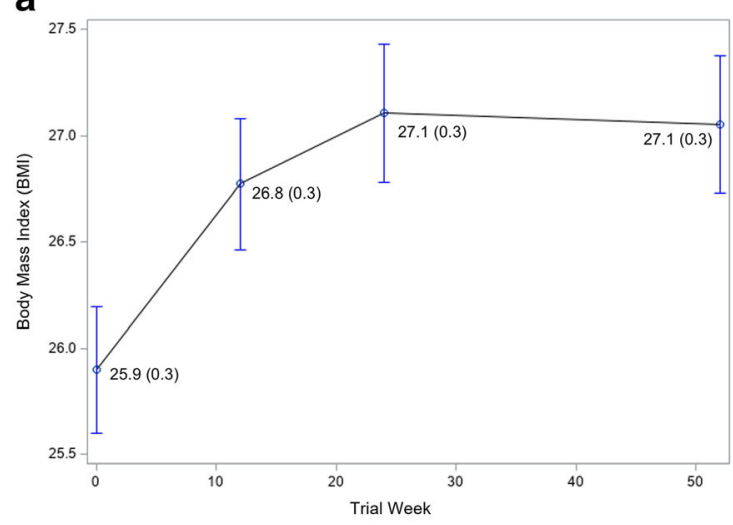

Fig. 1 Changes in mean body mass index (BMI) $\left(\mathrm{kg} / \mathrm{m}^{2}\right)$ over time. A Variation in unadjusted mean body mass index of all patients over 52 weeks; standard error is included in parentheses. B Sankey plot illustrating the

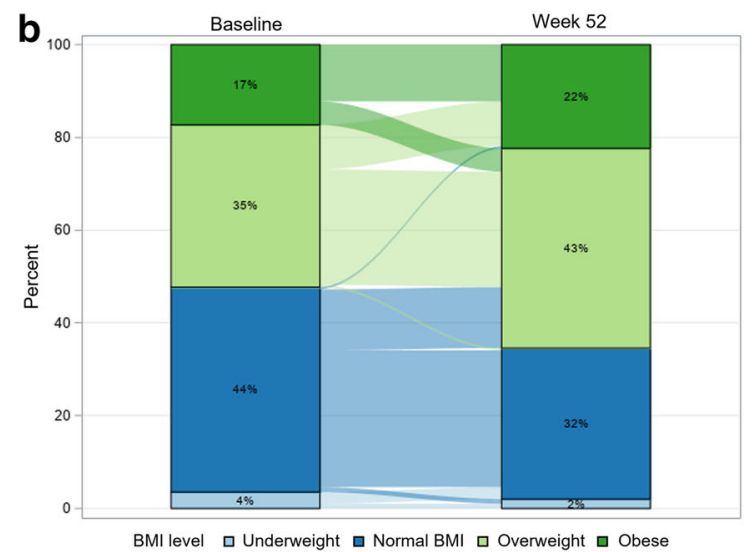

change in BMI category (underweight: $\mathrm{BMI}<18.5$; normal: BMI 18.5 to $<25$; overweight: BMI 25 to $<30$; obese: BMI $\geq 30$ ) of patients with available data at both baseline and week 52

Table 2 Body mass index change from week 0 to 52 by randomization group and disease status at baseline

\begin{tabular}{|c|c|c|c|c|c|c|}
\hline & $\begin{array}{l}\text { Relapsing } \\
\text { disease, } \\
N(\%) \\
(N=100)\end{array}$ & $\begin{array}{l}\text { Newly } \\
\text { diagnosed } \\
\text { disease, } N(\%) \\
(N=97)\end{array}$ & $p$ value & $\begin{array}{l}\text { Randomized } \\
\text { to tocilizumab, } \\
N(\%) \\
(N=115)\end{array}$ & $\begin{array}{l}\text { Randomized to } \\
\text { prednisone- } \\
\text { only, } \\
N(\%)(N=82)\end{array}$ & $p$ value \\
\hline$\geq 5 \mathrm{~kg} / \mathrm{m}^{2}$ decrease & $0(0)$ & $0(0)$ & 0.05 & $0(0)$ & $0(0)$ & 0.91 \\
\hline$>2$ to $<5 \mathrm{~kg} / \mathrm{m}^{2}$ decrease & $10(10)$ & $2(2)$ & & $6(5)$ & $6(7)$ & \\
\hline $\begin{array}{l}0-2 \mathrm{~kg} / \mathrm{m}^{2} \text { increase or } \\
\text { decrease }\end{array}$ & $66(66)$ & $60(62)$ & & $73(63)$ & $53(65)$ & \\
\hline$>2$ to $<5 \mathrm{~kg} / \mathrm{m}^{2}$ increase & $22(22)$ & $32(33)$ & & $33(29)$ & $21(26)$ & \\
\hline$\geq 5 \mathrm{~kg} / \mathrm{m}^{2}$ increase & $2(2)$ & $3(3)$ & & $3(3)$ & $2(2)$ & \\
\hline
\end{tabular}

remained stable at $27.1 \pm 4.5$ at 52 weeks $(p=0.01$ for change from 0 to 24 weeks and $p=0.91$ for change from 24 to 52 weeks) (Fig. 1A). BMI change was most notable over the first 24 weeks of the study, with patients gaining a mean of $1.1 \pm 1.7 \mathrm{~kg} / \mathrm{m}^{2}$ during weeks $0-24$. BMI change from weeks 24 to 52 was $0.0 \pm 1.3 \mathrm{~kg} / \mathrm{m}^{2}$. Regarding BMI category changes, $41(21 \%)$ had a decrease in BMI, $97(49 \%)$ had an increase of 0 to $2 \mathrm{~kg} / \mathrm{m}^{2}, 54(27 \%)$ had an increase of $>2$ to $5 \mathrm{~kg} / \mathrm{m}^{2}$, and five (3\%) had an increase of $>5 \mathrm{~kg} / \mathrm{m}^{2}$. Figure $1 \mathrm{~B}$ demonstrates the change in BMI status for patients between 0 and 52 weeks. Between patients with relapsing versus newly diagnosed disease, more patients with relapsing disease experienced decreases in BMI, and fewer patients with relapsing disease experienced $\mathrm{a}>2$ to $<5 \mathrm{~kg}$ / $\mathrm{m}^{2}$ increase in BMI (22 vs. $\left.32 \%\right)(p=0.05$ for differences across all categories) (Table 2). Patients randomized to tocilizumab had similar changes across BMI categories compared with those randomized to prednisone-only ( $p=0.91$ for differences across all categories) (Table 2).

\section{Factors Associated with BMI Change on Mixed-Effects Univariable and Multivariable Analyses}

In unadjusted analyses including all patients, the cumulative prednisone dose over 52 weeks 
was associated with an increase in BMI (ranging from $\beta=0.94 \mathrm{~kg} / \mathrm{m}^{2}$ for $0-1 \mathrm{~g}$ exposure to $\beta=1.40 \mathrm{~kg} / \mathrm{m}^{2} \quad$ for $\geq 4 \mathrm{~g}$ exposure; $p$ for trend $<0.001$ ) as was relapsing disease ( $\beta=1.57 \mathrm{~kg} / \mathrm{m}^{2}$ compared to those with newly diagnosed disease; $p=0.01$ ). Neither randomization to tocilizumab $\left(\beta=0.34 \mathrm{~kg} / \mathrm{m}^{2}\right.$ compared to prednisone-only; $p=0.56$ ) nor flares $\left(\beta=0.14 \mathrm{~kg} / \mathrm{m}^{2} ; p=0.65\right)$ were associated with BMI change on univariable analysis (Table 3). In fully adjusted analyses, the cumulative prednisone dose over 52 weeks was associated with increase in BMI (ranging from $\beta=0.92 \mathrm{~kg} / \mathrm{m}^{2}$ for $0-1 \mathrm{~g}$ exposure to $\beta=1.45 \mathrm{~kg} / \mathrm{m}^{2}$ for $\geq 4 \mathrm{~g}$ exposure; $p$ for trend $<0.001$ ) (Table 3 ), relapsing disease was independently associated with a lower increase in BMI $\left(\beta=-0.42 \mathrm{~kg} / \mathrm{m}^{2}\right.$ compared to those with newly diagnosed disease; $p=0.002)$, and disease flares during the trial were associated with a numerically lower BMI increase $\left(\beta=-0.10 \mathrm{~kg} / \mathrm{m}^{2}\right.$ per flare; $\left.p=0.15\right)$. Randomization to tocilizumab was not associated with BMI change $\left(\beta=0.11 \mathrm{~kg} / \mathrm{m}^{2}\right.$ compared to prednisone-only; $p=0.39$ ). Results were generally similar in subgroup analyses of those with newly diagnosed and relapsing disease, with the exception of flares, which were associated with a decrease in BMI in patients with newly diagnosed disease $\left(\beta=-0.18 \mathrm{~kg} / \mathrm{m}^{2}\right.$ per flare; $p=0.03$ ) (Table 4 ) but not in patients with relapsing disease $\left(\beta=-0.04 \mathrm{~kg} / \mathrm{m}^{2}\right.$ per flare; $p=0.73$ ) (Table 5).

Table 3 Multivariable mixed-effects modeling evaluating body mass index (BMI) change according to glucocorticoid exposure and other covariates in all patients

\begin{tabular}{|c|c|c|c|c|}
\hline \multirow[t]{2}{*}{ Exposure variable } & \multicolumn{2}{|l|}{ Unadjusted } & \multicolumn{2}{|l|}{ Multivariable adjusted* } \\
\hline & $\begin{array}{l}\text { Estimate (beta coefficient } \\
\text { and } 95 \% \mathrm{CI} \text { ) }\end{array}$ & $p$ value & $\begin{array}{l}\text { Estimate (beta coefficient } \\
\text { and } 95 \% \mathrm{CI} \text { ) }\end{array}$ & $p$ value \\
\hline \multicolumn{5}{|l|}{ Cumulative prednisone exposure } \\
\hline $0 \mathrm{~g}$ & Ref & & Ref & \\
\hline$>0$ to $<1 \mathrm{~g}$ & $0.90(0.67,1.13)$ & $<0.001^{* *}$ & $0.89(0.65,1.13)$ & $<0.001^{* *}$ \\
\hline$\geq 1$ to $<2$ g. $0-6-23$ & $0.94(0.75,1.12)$ & & $0.92(0.73,1.11)$ & \\
\hline$\geq 2$ to $<3 \mathrm{~g}$ & $1.08(0.78,1.39)$ & & $1.12(0.80,1.44)$ & \\
\hline$\geq 3$ to $<4 \mathrm{~g}$ & $1.42(0.98,1.86)$ & & $1.43(0.96,1.89)$ & \\
\hline$\geq 4 \mathrm{~g}$ & $1.40(0.91,1.89)$ & & $1.45(0.95,1.95)$ & \\
\hline Randomization to tocilizumab & $0.34(-0.82,1.51)$ & 0.56 & $0.11(-0.15,0.37)$ & 0.39 \\
\hline Flares (per flare) & $0.14(-0.47,0.76)$ & 0.65 & $-0.10(-0.24,0.037)$ & 0.15 \\
\hline Relapsing disease & $1.57(0.42,2.71)$ & 0.01 & $-0.42(-0.68,-0.15)$ & 0.002 \\
\hline Age (per year) & $-0.02(-0.10,0.05)$ & 0.56 & $-0.004(-0.02,0.01)$ & 0.60 \\
\hline Male sex & $1.68(0.26,3.09)$ & 0.02 & $-0.06(-0.35,0.24)$ & 0.69 \\
\hline Baseline BMI (per $\mathrm{mg} / \mathrm{m}^{2}$ ) & $0.97(0.94,1.00)$ & $<0.0001$ & $0.98(0.95,1.02)$ & $<0.001$ \\
\hline $\begin{array}{l}\text { Baseline prednisone } \\
\text { dose }>30 \mathrm{mg} \text { daily }\end{array}$ & $-0.75(-1.91,0.41)$ & 0.20 & $0.09(-0.18,0.36)$ & 0.51 \\
\hline
\end{tabular}

${ }^{*}$ Multivariable adjusted model adjusted for all of the following: age, sex, baseline BMI, baseline prednisone dose, cumulative prednisone exposure, relapsing disease, randomization to tocilizumab, and flares, where the covariate is not the exposure of interest

${ }^{* *} p$ value for trend across cumulative prednisone categories 
Due to the change in direction of the beta coefficients between the unadjusted and adjusted mixed-effects models for relapsing disease and flares, additional analyses were performed. Because patients with relapsing disease had a higher BMI at baseline, we sequentially added covariates in sensitivity analyses and noted that the direction of the association changed when baseline BMI was incorporated into the model. Similarly, since patients who flared received additional doses of prednisone, we sequentially added covariates to these models and found that adjusting for cumulative prednisone and baseline BMI were associated with changes in the direction of the association between flare and BMI.

\section{BMI Change and Relapsing Disease at Baseline}

Given that relapsing disease was associated with a smaller increase in BMI than newly diagnosed disease, we evaluated these disease type subgroups further. Over the 52-week trial, patients with relapsing disease at baseline had no significant change in BMI between 0 and 52 weeks (26.9 vs. $27.6 \mathrm{~kg} / \mathrm{m}^{2} ; p=0.27$ ) whereas those with newly diagnosed disease had a significant increase ( 24.8 vs. $\left.26.5 \mathrm{~kg} / \mathrm{m}^{2} ; p<0.01\right)$. Patients with relapsing disease had no significant change between 0 and 24 weeks or between 24 and 52 weeks (Fig. 2). The increase in BMI among patients with newly diagnosed disease was

Table 4 Multivariable mixed-effects modeling evaluating body mass index (BMI) change according to glucocorticoid exposure and other covariates in patients with newly diagnosed disease

\begin{tabular}{|c|c|c|c|c|}
\hline \multirow[t]{2}{*}{ Exposure variable } & \multicolumn{2}{|l|}{ Unadjusted } & \multicolumn{2}{|l|}{ Multivariable adjusted* } \\
\hline & $\begin{array}{l}\text { Estimate (beta coefficient } \\
\text { and } 95 \% \mathrm{CI} \text { ) }\end{array}$ & $p$ value & $\begin{array}{l}\text { Estimate (beta coefficient } \\
\text { and } 95 \% \mathrm{CI} \text { ) }\end{array}$ & $p$ value \\
\hline \multicolumn{5}{|l|}{ Cumulative prednisone exposure } \\
\hline $0 \mathrm{~g}$ & Ref & & Ref & \\
\hline$>0$ to $<1 \mathrm{~g}$ & $1.29(1.01,1.56)$ & $<0.001^{* *}$ & $1.23(0.97,1.48)$ & $<0.001^{* *}$ \\
\hline$\geq 1$ to $<2 \mathrm{~g}$ & $1.19(0.97,1.42)$ & & $1.20(0.98,1.43)$ & \\
\hline$\geq 2$ to $<3 \mathrm{~g}$ & $1.58(1.16,2.00)$ & & $1.61(1.15,2.08)$ & \\
\hline$\geq 3$ to $<4 \mathrm{~g}$ & $1.97(1.30,2.65)$ & & $1.94(1.21,2.66)$ & \\
\hline$\geq 4 \mathrm{~g}$ & $1.70(1.20,2.21)$ & & $1.75(1.24,2.26)$ & \\
\hline Randomization to tocilizumab & $1.11(-0.27,2.49)$ & 0.11 & $0.10(-0.24,0.44)$ & 0.56 \\
\hline Flares (per flare) & $0.15(-0.44,0.74)$ & 0.62 & $-0.18(-0.34,-0.02)$ & 0.03 \\
\hline Age (per year) & $-0.02(-0.11,0.07)$ & 0.60 & $-0.015(-0.04,0.01)$ & 0.16 \\
\hline Male sex & $1.26(-0.49,3.00)$ & 0.15 & $0.03(-0.30,0.36)$ & 0.87 \\
\hline Baseline BMI (per mg/m²) & $1.02(0.98,1.06)$ & $<0.0001$ & $1.02(0.98,1.05)$ & $<0.0001$ \\
\hline $\begin{array}{l}\text { Baseline prednisone } \\
\text { dose }>30 \mathrm{mg} \text { daily }\end{array}$ & $-0.66(-2.22,0.91)$ & 0.41 & $-0.40(-0.75,-0.05)$ & 0.03 \\
\hline
\end{tabular}

${ }^{*}$ Multivariable adjusted model adjusted for all of the following: age, sex, baseline BMI, baseline prednisone dose, cumulative prednisone exposure, relapsing disease, randomization to tocilizumab, and flares, where the covariate is not the exposure of interest

${ }^{* *} p$ value for trend across cumulative prednisone categories 
Table 5 Multivariable mixed-effects modeling evaluating body mass index (BMI) change according to glucocorticoid exposure and other covariates in patients with relapsing disease

\begin{tabular}{|c|c|c|c|c|}
\hline \multirow[t]{2}{*}{ Exposure variable } & \multicolumn{2}{|l|}{ Unadjusted } & \multicolumn{2}{|l|}{ Multivariable adjusted* } \\
\hline & $\begin{array}{l}\text { Estimate (beta coefficient } \\
\text { and } 95 \% \mathrm{CI} \text { ) }\end{array}$ & $p$ value & $\begin{array}{l}\text { Estimate (beta coefficient } \\
\text { and } 95 \% \mathrm{CI} \text { ) }\end{array}$ & $p$ value \\
\hline \multicolumn{5}{|l|}{ Cumulative prednisone exposure } \\
\hline $0 \mathrm{~g}$ & Ref & & Ref & \\
\hline$>0$ to $<1 \mathrm{~g}$ & $0.65(0.34,0.96)$ & $<0.001^{* *}$ & $0.69(0.35,1.02)$ & $<0.001^{* *}$ \\
\hline$\geq 1$ to $<2 \mathrm{~g}$ & $0.66(0.36,0.95)$ & & $0.60(0.29,0.90)$ & \\
\hline$\geq 2$ to $<3 \mathrm{~g}$ & $0.57(0.18,0.97)$ & & $0.59(0.17,1.00)$ & \\
\hline$\geq 3$ to $<4 \mathrm{~g}$ & $0.90(0.36,1.45)$ & & $0.92(0.36,1.47)$ & \\
\hline$\geq 4 \mathrm{~g}$ & $1.12(0.29,1.94)$ & & $1.17(0.34,2.01)$ & \\
\hline Randomization to tocilizumab & $-0.23(-2.00,1.53)$ & 0.79 & $0.18(-0.15,0.52)$ & 0.28 \\
\hline Flares (per flare) & $0.10(-0.89,1.08)$ & 0.84 & $-0.04(-0.26,0.18)$ & 0.73 \\
\hline Age (per year) & $-0.02(-0.14,0.09)$ & 0.70 & $-0.01(-0.01,0.03)$ & 0.38 \\
\hline Male sex & $2.06(-0.07,4.19)$ & 0.06 & $-0.13(-0.57,0.31)$ & 0.56 \\
\hline Baseline BMI (per mg/m²) & $0.96(0.92,1.01)$ & $<0.0001$ & $0.97(0.93,1.01)$ & $<0.0001$ \\
\hline $\begin{array}{l}\text { Baseline prednisone } \\
\text { dose }>30 \mathrm{mg} \text { daily }\end{array}$ & $-0.14(-1.91,1.64)$ & 0.88 & $0.62(0.26,0.98)$ & 0.001 \\
\hline
\end{tabular}

${ }^{*}$ Multivariable adjusted model adjusted for all of the following: age, sex, baseline BMI, baseline prednisone dose, cumulative prednisone exposure, relapsing disease, randomization to tocilizumab, and flares, where the covariate is not the exposure of interest

${ }^{* *} p$ value for trend across cumulative prednisone categories

observed between 0 and 24 weeks but not between 24 and 52 weeks (Fig. 2).

\section{BMI Change and Flares Across Treatment Arms Over 52 Weeks}

Patients randomized to tocilizumab received far less prednisone compared with those who were randomized to prednisone-only (median of 1583 vs. $3607 \mathrm{mg} ; p<0.001)$ and had fewer flares (median of 0 vs. $1 ; p<0.001$ ) but experienced similar changes in BMI (mean of 1.2 vs. $1.1 \mathrm{~kg} / \mathrm{m}^{2} ; p=0.31$ ) (Table 6). Similar results were seen when assessing BMI change and cumulative glucocorticoid exposure at 24 weeks and when evaluating results in patients with either newly diagnosed or relapsing disease.

\section{Analyses with Primary Outcome of Weight Change}

In addition to BMI, we also analyzed weight change $(\mathrm{kg})$ and found overall similar results. In the multivariable, fully adjusted mixed-effects model, cumulative prednisone exposure was independently associated with weight change with increasing estimates in increasing exposure categories. Relapsing disease and flares during the trial (particularly among newly diagnosed subjects) were both associated with numerically less weight gain, but neither reached statistical significance. 


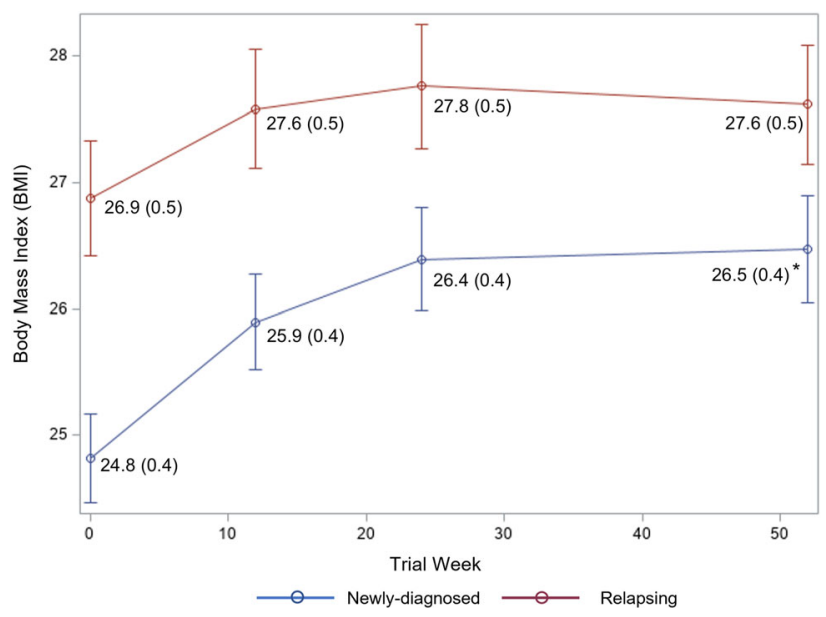

Fig. 2 Variation in body mass index (BMI) $\left(\mathrm{kg} / \mathrm{m}^{2}\right)$ over time by subgroup. BMI values represent unadjusted mean values. Standard error is included in parentheses. ${ }^{*}$ Represents a significant change from baseline BMI $(p<0.01)$

Table 6 BMI change and cumulative prednisone exposure from weeks 0 to 52 in tocilizumab and prednisone-only groups

\begin{tabular}{lllc}
\hline & $\begin{array}{l}\text { Randomized to tocilizumab } \\
(\boldsymbol{N}=\mathbf{1 4 9})\end{array}$ & $\begin{array}{l}\text { Randomized to prednisone-only } \\
(\boldsymbol{N}=\mathbf{1 0 1})\end{array}$ & $\boldsymbol{p}$ value \\
\hline $\begin{array}{l}\text { Cumulative prednisone }(\mathrm{mg}), \\
\text { median }(\mathrm{IQR})\end{array}$ & $1583(1113,2745)$ & $3607(2330,5323)$ & $<0.001$ \\
Flares, median $(\mathrm{IQR})$ & $0(0,1)$ & $1(0,2)$ & $<0.001$ \\
BMI change $\left(\mathrm{kg} / \mathrm{m}^{2}\right)$, mean $(\mathrm{SD})$ & $1.2(1.9)$ & $1.1(2.1)$ & 0.31 \\
\hline
\end{tabular}

\section{DISCUSSION}

Using data from a large, randomized trial of GCA, we confirmed that BMI change during the treatment of GCA is significantly associated with cumulative GC exposure. Several factors besides GC exposure, however, contribute to BMI change. Patients with higher baseline BMI had a greater increase in BMI, whereas relapsing disease at baseline and disease flares in newly diagnosed patients were independently associated with a lower increase in BMI. Therefore, effective disease control also contributes to an increase in BMI among GCA patients, demonstrating that the relationship between GC use and BMI increase in GCA is more complex than a simple tabulation of the number of milligrams of prednisone used over the course of treatment. Regardless of the treatment group to which patients were assigned in the trial, systemic inflammation associated with poor disease control (i.e., flares of GCA) seems to counterbalance the weight gain one might expect from GC exposure. Similar findings pertaining to inflammation, weight loss, and frailty have also been reported in other conditions [11]. Indeed, regardless of the treatment group in our study, the patients who experienced disease flares had BMI changes similar to those who did not flare on unadjusted analyses-despite receiving a significantly higher cumulative glucocorticoid dose over 52 weeks.

We also observed that patients with relapsing disease at baseline gained less weight over 52 weeks than those with newly diagnosed disease despite the fact that these two subgroups received similar amounts of prednisone. Similar 
observations have been made in studies of AAV [8]. The reasons why patients with relapsing disease experienced less weight gain are not entirely clear. Notably, those with relapsing disease had higher baseline BMI than those with newly diagnosed disease; possible explanations for this include prior GC exposure or that patients with relapsing disease may have experienced weight gain following their initial disease diagnosis prior to enrollment in the GiACTA trial. This may have then contributed to lower observed BMI increases during the trial. That said, as patients with higher baseline BMI generally had greater increases in BMI, these baseline differences alone would not explain the differences in BMI change by week 52 between those with relapsing versus newly diagnosed disease. We hypothesize that the patients with relapsing disease at baseline who are experienced users of GC may have made modifications in diet or lifestyle that contributed to a lower amount of weight gain. Studies in both rheumatoid arthritis and AAV (e.g., Wegener's Granulomatosis Etanercept Trial [WGET] and Rituximab in AAV [RAVE] trials) have found an association between improvement in disease activity and increase in weight or BMI in the setting of GC use $[6,7,12]$. These studies, however, have shown mixed results with regard to the independent association between GC dose and changes in BMI [6-8].

Our results are concordant with those from the RAVE trial, in which both cumulative GC dose and improvement in disease activity were associated with an increase in BMI. The cumulative GC dose was markedly higher in both the WGET and RAVE trials than in GiACTA, perhaps accounting for the fact that $22 \%$ of patients in the WGET trial gained at least $10 \mathrm{~kg}$ over 1 year compared with only $7 \%$ in the GiACTA trial. Differences in age and sex at baseline between the two trial populations might also have contributed to the differences observed. The mean age at entry in GiACTA was approximately 20 years older than in RAVE, and $75 \%$ of the GiACTA patients were women compared with only $50 \%$ in RAVE. Findings from the RAVE trial also supported the relationship between effective disease control and a tendency toward BMI increase: patients randomized to rituximab in that trial were more likely to achieve disease remission and received less cumulative prednisone, yet had a greater increase in BMI.

Our study has numerous strengths. Due to the clinical trial setting in which these data were collected, accurate cumulative prednisone doses, which can be difficult to capture in routine clinical care, were available for all patients. Other clinical variables of interest were also collected in a systematic manner. The randomized nature of GiACTA also permitted us to leverage randomization to compare the effect of tocilizumab versus no tocilizumab on change in BMI. Our study also has certain limitations. First, data from controlled trials are not always generalizable to routine clinical care. Indeed, some data suggest that the doses of GC used in clinical practice are in fact considerably higher than those used in GiACTA; this may contribute to greater degrees of BMI change in clinical practice compared to what we observed [13]. Therefore, caution should be employed when attempting to extrapolate our results to general practice, and similar studies in real-world populations should follow. Second, subjects' baseline weights prior to the onset of disease activity were unavailable, so the extent to which weight gained during the trial corresponded to an increase in weight over their baseline weight before disease onset could not be ascertained. Third, cumulative GC dose received prior to enrolling in the trial was not available. This may bias the results toward lower apparent BMI gain if some BMI increase occurred prior to baseline in the setting of GC exposure and treatment of inflammatory disease. In addition, the potential effect on body mass index of inflammation related to flares occurring before baseline (e.g., in relapsing patients) is unknown. Last, although we addressed the association of various clinically relevant factors with BMI and weight change, we are unable to comment specifically on changes in body composition, which may have different associations, because data on body composition were not collected in the GiACTA trial. Analyses of the impact of treatment on body composition should be considered in future studies. 


\section{CONCLUSIONS}

In conclusion, although GC use and weight gain are linked tightly in the minds of both providers and patients, our study demonstrates that these relationships are complex. Cumulative GC exposure over 52 weeks is significantly associated with change in BMI but success or failure in controlling disease activity with treatment also affects changes in BMI. A modest increase in BMI may in fact be an indicator of effective disease control.

\section{ACKNOWLEDGEMENTS}

We would like to acknowledge all patients who were involved in the original trial. We are also pleased to acknowledge the outstanding work of the full GiACTA research group.

Funding. NJP is supported by the National Institutes of Health Ruth L. Kirschstein Institutional National Research Service Award [T32AR-007258]. ZSW is funded by NIH/NIAMS [K23AR073334 and L30AR070520]. The authors funded the journal's Rapid Service Fee.

Authorship. All named authors meet the International Committee of Medical Journal Edits (ICMJE) criteria for authorship for this article, take responsibility for the integrity of the work as a whole, and have given their approval for this version to be published.

Authors' Contributions. All authors contributed to the study conception and design. Material preparation and data collection were performed by Naomi Patel, John Stone, and Sebastian Unizony. Methodology and analysis were performed by Xiaoqing $\mathrm{Fu}$ and Yuqing Zhang. The first draft of the manuscript was written by Naomi Patel, and all authors provided input and revisions on prior versions of the manuscript. All authors read and approved the final manuscript.

Disclosures. Sebastian Unizony has received research funding from Genentech and consulting fees from Kiniksa, Janssen, and Sanofi. Zachary Wallace reports research support from Bristol-Myers Squib and Sanofi and consulting fees from Viela Bio and MedPace. John Stone is a consultant for and has received research funding from Genentech and Roche. John Stone was the Principal Investigator for the Trial of Tocilizumab in Giant Cell Arteritis. Naomi Patel, Xiaoqing Fu, Yuqing Zhang, and Hyon Choi report no competing interests.

Compliance with Ethics Guidelines. The original clinical trial (Trial of Tocilizumab in Giant Cell Arteritis) was approved by the respective Institutional Review Board at each participating institution and was conducted in accordance with the Declaration of Helsinki. Written informed consent was obtained from all study participants.

Data Availability. Data generated during and/or analyzed during the current study may be made available upon request by contacting the corresponding author, Dr. John H. Stone.

Open Access. This article is licensed under a Creative Commons Attribution-NonCommercial 4.0 International License, which permits any non-commercial use, sharing, adaptation, distribution and reproduction in any medium or format, as long as you give appropriate credit to the original author(s) and the source, provide a link to the Creative Commons licence, and indicate if changes were made. The images or other third party material in this article are included in the article's Creative Commons licence, unless indicated otherwise in a credit line to the material. If material is not included in the article's Creative Commons licence and your intended use is not permitted by statutory regulation or exceeds the permitted use, you will need to obtain permission directly from the copyright holder. To view a copy of this licence, visit http://creativecommons.org/licenses/by$\mathrm{nc} / 4.0 /$. 


\section{REFERENCES}

1. Costello R, Patel R, Humphreys J, McBeth J, Dixon WG. Patient perceptions of glucocorticoid side effects: a cross-sectional survey of users in an online health community. BMJ Open. 2017; 7: e014603.

2. Morin C, Fardet L. Systemic glucocorticoid therapy: risk factors for reported adverse events and beliefs about the drug. A cross-sectional online survey of 820 patients. Clin Rheumatol. 2015;34:2119-26.

3. Arena C, Morin AS, Blanchon T, et al. Impact of glucocorticoid-induced adverse events on adherence in patients receiving long-term systemic glucocorticoid therapy. Br J Dermatol. 2010;163:832-7.

4. Movahedi M, Costello R, Lunt M, Pye SR, Sergeant JC, Dixon WG. Oral glucocorticoid therapy and allcause and cause-specific mortality in patients with rheumatoid arthritis: a retrospective cohort study. Eur J Epidemiol. 2016;31:1045-55.

5. Del Rincon I, Battafarano DF, Restrepo JF, Erikson JM, Agustin E. Glucocorticoid dose thresholds associated with all-cause and cardiovascular mortality in rheumatoid arthritis. Arthritis Rheumatol. 2014;66:264-72.

6. Jurgens MS, Jacobs JW, Geenen R, et al. Increase of body mass index in a tight controlled methotrexate-based strategy with prednisone in early rheumatoid arthritis: side effect of the prednisone or better control of disease activity? Arthritis Care Res (Hoboken). 2013;65:88-93.
7. Wallace ZS, Miloslavsky EM, Cascino M, et al. Effect of disease activity, glucocorticoid exposure, and rituximab on body composition during induction treatment of antineutrophil cytoplasmic antibodyassociated vasculitis. Arthritis Care Res (Hoboken). 2017;69:1004-10.

8. Wung PK, Anderson T, Fontaine KR, et al. Effects of glucocorticoids on weight change during the treatment of Wegener's granulomatosis. Arthritis Rheum. 2008;59:746-53.

9. Stone JH, Tuckwell K, Dimonaco S, et al. Trial of tocilizumab in giant-cell arteritis. $\mathrm{N}$ Engl J Med. 2017;377:317-28.

10. Miloslavsky EM, Naden RP, Bijlsma JW, et al. Development of a Glucocorticoid Toxicity Index (GTI) using multicriteria decision analysis. Ann Rheum Dis. 2017;76:543-6.

11. Soysal P, Stubbs B, Lucato P, et al. Inflammation and frailty in the elderly: a systematic review and meta-analysis. Ageing Res Rev. 2016;31:1-8.

12. Bakker MF, Jacobs JWG, Welsing PMJ, et al. Lowdose prednisone inclusion in a methotrexate-based, tight control strategy for early rheumatoid arthritis. Ann Intern Med. 2012;156:329-39.

13. Gale S, Wilson JC, Chia J, et al. Risk associated with cumulative oral glucocorticoid use in patients with giant cell arteritis in real-world databases from the USA and UK. Rheumatol Ther. 2018;5:327-40. 